\title{
A test of the peak-end rule with extended autobiographical events
}

\author{
Simon Kemp, Christopher D. B. Burt, and Laura Furneaux \\ University of Canterbury, Christchurch, New Zealand
}

\begin{abstract}
Forty-nine students went on vacation for an average of 7 days and sent daily text messages about the happiness they had experienced over the previous $24 \mathrm{~h}$. After their vacation, they were questioned on the overall happiness they had experienced and were asked to recall the daily record of their happiness. The duration of the vacation had no effect on the subsequent evaluations, and participants were not able to recall the detail of their day-to-day changes in happiness. A number of summary measures provided reasonable prediction of the recalled overall happiness of the vacation. The peak-end rule was not an outstandingly good predictor. Overall, the results indicate much reconstruction of the affective states.
\end{abstract}

This article reports a study in which people made daily reports on their level of happiness during a vacation. Subsequently, they were asked to recall the happiness of their holiday experience. There seems to be little previous research on how the happiness experienced during an autobiographical event is recalled, and the chief aim of the study was to test whether the peak-end rule (see, e.g., Fredrickson \& Kahneman, 1993) would apply to such an event.

There has been growing interest in how people summarize the hedonic value of their experiences (see, e.g., Ariely \& Carmon, 2003; Kahneman, 2000a, 2000b). On what basis do people judge that a particular extended event was happy or miserable? Kahneman (2000b) drew attention to the difference between a memory-based and a moment-based approach to happiness. On the one hand, we might ask someone to give a moment-by-moment account of how happy he or she is feeling during a particular experience. A possible measure of the total happiness experienced might then be the sum of the happiness of all the different moments. Alternatively, we could wait until after the end of the experience and then ask the person how happy the whole experience was. Naively, one might expect that these two values would be the same. In fact, research to date suggests they are not.

For example, Fredrickson and Kahneman (1993) asked participants to provide a continuous record of their affect while viewing pleasant and unpleasant film clips, and subsequently asked them for an overall estimate of the pleasure or discomfort experienced. An attempt was made to make the number of affect-provoking episodes in the clips independent of their duration, and a striking result was that the overall estimates of the pleasure or discomfort were not much related to the duration of the clip. However, the global evaluations of the pleasant clips were quite well predicted $(r=.78)$ by a simple average of the peak affect (i.e., the pleasantness of the most pleasant single moment) and the final experienced affect.

Research has also been carried out on real-life experiences. Redelmeier and Kahneman (1996) had patients who were undergoing painful medical treatments (colonoscopy or lithotripsy) keep a continuous record of the intensity of the pain that they experienced, and then subsequently asked them to rate the total amount of pain from the procedure. The overall rating was again unrelated to the duration of the treatment and well predicted $(r=.67$ for colonoscopy, $r=.65$ for lithotripsy) from the peak pain and end pain. A counterintuitive prediction of this research - that adding on an extra short low-pain episode should lower the subsequent pain evaluation of the whole experience - was later confirmed (Redelmeier, Katz, \& Kahneman, 2003).

A number of other experiments have investigated both duration neglect and the peak-end rule, generally confirming their validity as well as indicating the importance of other variables - for example, whether the experience becomes more or less pleasant during its course (see, e.g., Ariely \& Loewenstein, 2000; Ariely \& Zauberman, 2000; Schreiber \& Kahneman, 2000). However, Ariely and Carmon (2003) pointed out that, partly for reasons of practicality, the research has tended to focus on relatively brief experiences that are unpleasant rather than pleasant, and on experiences that do not mix the pleasant and unpleasant. Indeed, it is not completely clear how the peak-end rule should be applied to mixed experiences. Should the peak be taken from the peak pleasant moment or from the "trough" unpleasant moment, since either could be taken as the extreme of the experience? Alternatively, should both the peak and the trough be taken into account? This issue was investigated empirically in our study. 
We investigated a type of experience-going on holidays - that we expected to produce mixed but generally pleasant emotions. It resembled previously investigated experiences in having a definite beginning and end. This seemed to be an important requirement for the evaluation of the peak-end rule, and one that would not be fulfilled by simply investigating people's happiness over a normal week, for example. Indeed, previous research has indicated that the beginnings and ends of events form an important part of the definition of the experience (see, e.g., Burt, Kemp, \& Conway, 2003, in press). We also chose to investigate holidays because they are an example of the kind of extended event that forms people's autobiographical memories (Burt, 1992), and we wanted to see if the peak-end rule applied to such memories. Indeed, the holidays that we studied were considerably longer than the experiences previously investigated.

There has now been extensive research on how people recall events from their past lives and how the recall of these events preserves, distorts, or omits features of the original experience. We summarize a few findings from this work that are relevant to the present article. (For more extensive summaries and current theories, see, e.g., Conway, 2005; Rubin, 1986, 1996, 2005; Shum, 1998; Thompson, Skowronski, Larsen, \& Betz, 1996.)

In general, we are unable to recall the details of many of our previous experiences and, indeed, many details may be reconstructed rather than remembered (see, e.g., Rubin, 1996). In addition, ordinary people may recall experiences quite inaccurately or in a way that has been greatly distorted. A striking example is that twins (and, more rarely, other pairs of people) sometimes disagree on whom a particular memory belongs to. So, for instance, twins might disagree on which of them actually won a spelling prize at school or which of them was involved in a nasty accident (Sheen, Kemp, \& Rubin, 2001). Much of the loss of detail can be explained simply by considering the enormous problems of storage and access that would be incurred if everything were remembered (Conway, 2005). However, it is also likely that people's recall is strongly affected by their goals, and that changes to these goals produce changes to what we actually remember (Conway, 2005; Conway \& Pleydell-Pearce, 2000). Much research has focused on which events or aspects of events are most likely to be remembered. For example, the beginnings and ends of events are often particularly well remembered (e.g., Burt et al., 2003), as are events that are subsequently important to us, or those that excited strong emotion at the time (Shum, 1998).

Autobiographical memory for past affect appears subject to the same general processes. People are not always able to recall their affect accurately; the intensity of remembered affect often appears to change with time, and what is recalled often shows evidence of reconstruction (see, e.g., Christianson \& Safer, 1996; Levine, 1997; Thomas \& Diener, 1990). Thus, it is quite likely that someone's memory of a holiday may be affected by reconstruction along the lines of "I was on holiday and remember swimming a lot with friends; therefore, I was happy." Cojuharenco (2007) recently reported studies in which one group of participants had an experience, and a second group of participants estimated the first group's affective evaluations of the experience. The second group thus was effectively asked to reconstruct the affect experienced by the first, a task that they often fulfilled with some success.

Researchers have frequently reported that both positive and negative affect fade with time, but that the latter fades faster (see, e.g., Walker, Vogl, \& Thompson, 1997). Remembered affect is also influenced by people's mood at the time of recall. For example, people who are depressed find it relatively difficult to recall memories of positive affect (e.g., Matt, Vázquez, \& Campbell, 1992; Teasdale, Taylor, \& Fogarty, 1980). However, unhappy people do not always recall unhappy incidents or recall neutral incidents as unhappy. The remembered affect also depends on the situation and current goals of the individual. For example, students suffering from homesickness tend to remember incidents from their life at home as happier than they probably were (Burt, Strongman, \& Costanzo, 1998). Walker, Skowronski, and Thompson (2003) suggest that the selectivity of our memory for affect helps to enhance our belief that life is pleasant.

Overall, the autobiographical memory research suggests that very few individuals could accurately recall a detailed profile of the way in which their happiness (or any other affect) changed over time, that only a small amount of affective information will be recalled at any appreciable time after the event, and that the remembered affect at different times of recall is likely to change. The question of precisely which information is most likely to be available and used in the affect retrieval process is not an easy one to answer, especially because the various measures will often correlate quite highly with one another. For example, the peak happiness experienced during an extended event might well also be the most memorable or most unusual episode in the event. In this context, note that Cojuharenco and Ryvkin (2007) found that the affective average of the peak and end of the experience and the affective average of the whole experience were often highly correlated in samples of previously published data.

If the peak-end rule is a good description of the way in which people recall the affect of their autobiographical memories, a likely mechanism for the result is that the peak affect and affect at the end of the experience are unusually well remembered. Moreover, we might expect that the overall happiness level recalled at a particular recall time will be highly correlated with how they recall the original peak and end affect levels at the same time. These predictions are tested below.

\section{METHOD}

We advertised for University of Canterbury students who were going away over the break between semesters to take part in a study of their holiday experiences. They were told that they would be paid for their participation. Forty-one students took part in both the text messaging and the first recall test. (One subsequently proved to have unusable data.) Twenty-four of these participants also took part in a second recall test. A further 10 participants also took part in a similar study over the summer break. Two participants had also formed part 
of the earlier intake. Throughout the following analysis, the separate holiday data from these 2 participants are treated as though they were recorded from different participants.

Nine of the final 49 participants were male. The median age was 20 , with a range from 18 to 51 years. Forty-three holidays were taken in New Zealand, 7 in Australia, and 1 in the United Kingdom. (New Zealand students often do travel beyond Australasia, but, in this case, such travelers had difficulty texting us from these destinations.) Five participants traveled alone.

\section{Text Message Task}

The task can be seen as an adaptation of Brewer's (1988) study in which participants responded to beepers. In our task, participants were asked to text our cell-phone once a day for every day that they were away. They were asked to text us six letters (A-F, each identifying a question) and one number (from the range 1-9) as a rating response to each of the six questions. (E.g., a day's text message might read "a6b5c5d7e8f4.") They were asked to send their messages at the end of each day.

The six questions asked were:

(1) Please rate how you feel right now (scale: 1 extremely unhappy to 9 extremely happy).

(2) Please rate how you felt in your best moment since you last texted us (scale: 1 extremely unhappy to 9 extremely happy).

(3) Please rate how you felt in your worst moment since you last texted us (scale: 1 extremely unhappy to 9 extremely happy).

(4) How would you rate the most significant events of the last 24 hours for their likely memorability (scale: 1 extremely unmemorable to 9 extremely memorable)?

(5) Averaging over the past 24 hours, have you been (scale: 1 extremely unhappy to 9 extremely happy)?

(6) Compared to your usual, everyday life, have the events of the past 24 hours been (scale: 1 extremely usual for your normal life to 9 extremely unusual for your normal life)?

One participant consistently recorded and rated her worst moments higher than her best moments, and her text scores were discarded. Participants were generally diligent in their message sending (sometimes reminders were sent), but 2 participants did not text us during the last few days of their holiday because their cell phones' batteries were flat, and they were unable to recharge them.

\section{First Recall Task}

Participants were individually tested between 2 and 16 days $(M=$ 8.8) after their final text message. They completed a questionnaire asking them to rate their overall feeling on their holiday, how they felt in the best and worst moments of their holiday, and how they rated the memorability and unusualness of their holiday (all scored on 1-9 scales, as was the case for the text task). In addition, they were asked for the duration of their holiday in days, the country they spent the most time in, who they went with, whether they had been to this place before, and their gender and age. Finally, they were presented with a template graph with days on the $x$-axis and rated happiness on the $y$-axis (using the 9-point scale), and they were asked to record on the graph how happy they were on each day of their holiday.

\section{Second Recall Task}

Participation in this task was not originally advertised, and not all of the earlier participants chose or were able to complete it. In the end, 27 second recall tests were performed. These tests took place about a month after the first recall task and between 36 and 47 days $(M=40.0)$ after the end of the holiday.

Again, participants were individually tested. They were first asked to rate how they had felt over the previous $24 \mathrm{~h}$ on a scale from 1 to 9 (scored as before). They were then asked to rate their overall feeling about their holiday, their best and worst moments, memorability, and unusualness (all rated as before). They also estimated the duration of their holiday in days, and they indicated any subsequent impact of their holiday and whether this impact was positive or negative. Finally, they graphed their recalled happiness for each day of their holiday as in the previous task.

\section{RESULTS}

\section{Measures}

Estimates of holiday duration were consistent across the recall tasks and with the number of text messages (except for the 2 participants whose cell-phone batteries expired). The durations ranged from 4 to 14 days, with an average of 7.5 days). Of the 27 participants who were asked this question, 5 reported a negative impact of their holiday. For example, they fell ill, had an accident, or learned while they were on holiday about the death of a friend at home. Such experiences serve as a reminder that holidays are not always uniformly happy experiences, as indeed some of our participants' results show.

A number of measures were calculated from the data of the individual holidays. These included happiness at the time of texting averaged over the holiday (average texttime happiness), the rated happiness of the best and worst moments of the entire holiday (i.e., the maximum of the daily rated best moments and the minimum of the daily rated worst moments), happiness of the previous $24 \mathrm{~h}$ averaged over the holiday (average 24-h happiness), the 24-h happiness of the most memorable day (averaged over the days if more than one day received that participant's top memorability rating), and the 24-h happiness of the most unusual day (similarly averaged if two or more days received the top unusualness rating). Four measures of the peak-end hypothesis were calculated from these results: peak-end text (the average of the rated happiness of the best moment and the final text rating), peak-end $24 \mathrm{~h}$ (average of the best moment and final 24-h rating), trough-end text (average of worst moment and the final text rating), and trough-end $24 \mathrm{~h}$ (average of the worst moment and final 24-h rating).

Table 1 presents comparisons between the overall happiness rating of the holiday in the first recall test and a number of the indices derived from the messages sent. For most indices, two different comparisons are made. First, how do the mean values compare with the overall test rating, and are there significant differences between them (as measured by a $t$ test)? Second, how well do the measures correlate (using Pearson correlation)? Both comparisons appear important: For example, if recalled happiness were well predicted by the peak-end text rating, we would expect both that the two means would be close and that there would be a high correlation between the two measures. The table also compares the average rated happiness of the holiday as recalled in Test 1, with the average happiness derived from the graph obtained in Test 1 .

Table 2 presents similar comparisons between the rating of holiday happiness in the second recall task and the message indices, as well as comparisons with the holiday happiness rating obtained from the first recall test and comparisons with the participants' rated happiness in the 
Table 1

Results Relating to the Prediction of Recalled Holiday Happiness at Test 1

\begin{tabular}{llll} 
Ratings & $M$ & $S D$ & $r$ \\
\hline
\end{tabular}

\begin{tabular}{llll}
\hline Happiness from text messages & & & \\
Overall holiday happiness & 6.8 & 1.4 & \\
Average at text times & $6.3^{* *}$ & 1.1 & $.43^{*}$ \\
Average of 24 h & $6.2^{* *}$ & 1.1 & $.64^{*}$ \\
Peak happiness & $8.5^{* * *}$ & 0.8 & .07 \\
Trough happiness & $2.4^{* * *}$ & 1.3 & .26 \\
Final text happiness & $6.2^{* *}$ & 1.7 & .25 \\
Final 24-h happiness & $6.2^{* *}$ & 1.6 & $.55^{*}$ \\
Happiness most memorable 24 h & 6.4 & 1.7 & $.63^{*}$ \\
Happiness most unusual 24 h & $6.1^{*}$ & 1.8 & $.59^{*}$ \\
First 24-h happiness & 6.5 & 1.5 & $.40^{*}$ \\
Composite happiness from text messages & & & \\
Peak end (last text) & $7.4^{*}$ & 1.1 & .22 \\
Peak end (last 24 h) & $7.3^{* *}$ & 0.9 & $.48^{*}$ \\
Trough end (last text) & $4.3^{* * *}$ & 1.2 & $.33^{*}$ \\
Trough end (last 24 h) & $4.3^{* * *}$ & 1.1 & $.52^{*}$ \\
Other measures & & & \\
Mean Graph 1 & $6.5^{*}$ & 1.0 & $.66^{*}$ \\
Holiday duration (days) & 7.7 & 4.2 & .06 \\
\hline
\end{tabular}

Note-Significant two-tailed $t$ test differences of the measure from the Test 1 overall holiday happiness rating are shown in the means column. Significant Pearson correlations with the overall Test 1 holiday rating are shown in the third column. ${ }^{*} p<.05 .{ }^{* *} p<.01 .{ }^{* * *} p<.001$.

$24 \mathrm{~h}$ preceding Test 2 . Note that the text message indices presented here may differ from those in Table 1 because fewer participants took part in the second recall task, and only the results from those participants are included.

Table 2

Results Relating to the Prediction of Recalled Holiday Happiness at Test 2

\begin{tabular}{llll}
\hline \multicolumn{1}{c}{ Ratings } & \multicolumn{1}{c}{$M$} & $S D$ & $r$ \\
\hline Happiness & & & \\
Overall holiday happiness & 6.8 & 1.6 & \\
Average at text times & $5.9^{* *}$ & 1.2 & $.57^{*}$ \\
Average of 24 h & $6.0^{* * *}$ & 1.3 & $.85^{*}$ \\
Peak happiness & $8.5^{* * *}$ & 0.9 & .18 \\
Trough happiness & $2.2^{* * *}$ & 1.1 & $.48^{*}$ \\
Final text happiness & $5.5^{* *}$ & 1.8 & .36 \\
Final 24-h happiness & $6.0^{* *}$ & 1.3 & $.60^{*}$ \\
Happiness most memorable 24 h & $6.2^{*}$ & 1.8 & $.73^{*}$ \\
Happiness most unusual 24 h & $6.1^{*}$ & 1.8 & $.78^{*}$ \\
First 24-h happiness & 6.5 & 1.5 & $.70^{*}$ \\
Composite happiness from text messages & & & \\
Peak end (last text) & 7.0 & 1.2 & .33 \\
Peak end (last 24 h) & 7.3 & 0.8 & $.57^{*}$ \\
Trough end (last text) & $3.9^{* * *}$ & 1.2 & $.47^{*}$ \\
Trough end (last 24 h) & $4.1^{* * *}$ & 1.0 & $.68^{*}$ \\
Other measures & & & \\
Mean Graph 2 & $6.1^{* *}$ & 1.2 & $.80^{*}$ \\
Holiday happiness rating (Test 1) & 6.7 & 1.6 & $.76^{*}$ \\
Happiness over 24 h before Test 2 & $5.3^{*}$ & 2.0 & -.34 \\
Holiday duration (days) & 7.7 & & -.30 \\
\hline
\end{tabular}

Note-Significant two-tailed $t$ test differences of the measure from the Test 2 overall holiday happiness rating are shown in the means column. Significant Pearson correlations with the overall Test 2 holiday happiness rating are shown in the third column. Mean ratings of the happiness measures texted during the holiday may differ from those in Table 1, because some respondents did not participate in Test $2 .{ }^{*} p<.05 .{ }^{* *} p<$ .01. ${ }^{* * *} p<.001$.

\section{Consistency of Happiness Recall}

We begin by considering how reliable and consistent the participants' estimates of their remembered happiness are, both within and between the two recall tests. If these memories were consistent within the tests, we would expect that the mean of the overall happiness rating would equal the mean of the graphed happiness ratings for that test and that the overall happiness rating would be very highly correlated with the mean of the graphed ratings. In fact, the correlations are moderately high and the average of the graphed happiness is slightly (but for both tests significantly) lower than the overall recalled happiness. Thus, within each test, there was reasonable but not perfect reliability.

Rated overall happiness of the holiday was moderately highly correlated between the two tests, and the two means were similar. We also calculated the correlation between the two sets of graphed happiness ratings for each participant who provided them. The correlations between the two sets of graphed happiness ratings were positive on average (mean $r=.33$ ), but extremely variable between individuals ( $S D$ of $r=.54)$. At the very extreme, 2 participants had correlations of 1 , and 1 participant had a correlation of -1 . Overall, the results indicate inconsistency in recall between the two tests.

\section{Prediction of Overall Recalled Happiness}

Neither test showed a significant relationship between the duration of the holiday and the rating of overall happiness.

Generally, the participants appear to have been happier on their holidays - both at the time and in retrospectthan in their normal lives. This conclusion derives from the comparison with participant happiness over the $24 \mathrm{~h}$ preceding Test 2 .

The means of the peak-end measures are significantly higher than the overall happiness ratings for the first recall test, whereas those for the trough-end measures are considerably lower for both tests. Correlations between the peak-end measures and the overall ratings are rather low; those for the trough-end measures are higher, but not higher than the average 24-h rating or the happiness of the most memorable 24-h period. The end measures based on the last text-time rating result in consistently lower correlations than those based on ratings of the last 24-h period of the holiday. The lower correlation for the peakend measures reflects in part the lack of variation between participants in their rating of the best moment, which 34 of 49 participants rated as 9 . In this context, note also the low correlation between peak happiness and the overall recalled happiness ratings.

The overall recalled happiness in the tests correlates moderately well with the happiness experienced in the most memorable $24-\mathrm{h}$ period (or periods), the happiness of the most unusual 24-h period, or the average of all the 24-h periods. It is difficult to decide between these predictors, since the two different measures - the size of the correlations and the distance between the means-do not always point in the same direction. It is noticeable, however, that although the correlations are moderately high, 
all three measures tend to underestimate mean recalled happiness (whereas the peak-end measure does not).

\section{Correlations Among Predictor Measures}

The different summary measures of overall happiness correlated positively and often quite highly. For some correlations, for example, the correlation of the peak-end measure with the final 24 -h rating $(r=.90, p<.05)$, a reasonably high correlation is virtually forced by the way the measures are constructed. However, some moderately high correlations - for example, a significant correlation $(r=.36)$ between the first and the last 24-h periodscannot be explained away as artifacts of this kind. An implication that is also apparent from Tables 1 and 2 is that most of these measures could serve as a reasonable summary measure of the happiness actually felt during the holiday, although not all equally well.

\section{Recall of Day-by-Day Happiness}

For each individual, Pearson product-moment correlations were calculated between the 24-h ratings of happiness sent at the time and the graphed happiness for both the first and second (where available) recall tests. The average of these correlations was .27 $(S D=.47)$ for the first and $.22(S D=.39)$ for the second test. Thus, the vast majority of the participants did not produce a very accurate recall of the day-by-day happiness of the segments of their holidays.

\section{Recall of Peak, Trough, and End Happiness}

Table 3 presents results relating to the question of how well the peak, trough, end, and first happiness ratings are remembered. Recall that in both tests, participants were asked to rate their happiness at the best and worst moments of their holiday. Recall of happiness from the start and end of the holiday was simply taken from the first and last 24-h periods on the participants' graphs. These values are compared with the first and final 24-h ratings (rather than with the ratings at the time the text was sent). The peak and trough happiness obtained from the daily holiday data correlate well with those recalled in Test 2, but less well with those recalled in Test 1 . The means show an increasing tendency for the peak happiness to be recalled as less happy with increasing time; the troughs are recalled as less unhappy on both recall tests. Generally, the table indicates that happiness during the first 24 -h period is recalled at least as well as the peak happiness or that from the last 24-h period.

Table 4 presents data concerning how well the overall happiness ratings during the first and second recall tests is predicted from what the participant recalls about the best moment and the last $24-\mathrm{h}$ period. The correlations indicate that the "remembered" peak-end measure gives a reasonable prediction of the overall happiness rating, but that the predictions are no better than those derived from the equivalent "remembered" rating of the first 24-h period. Moreover, the "remembered" peak-end measure is significantly too high an estimate for the average happiness rating estimated on Test 1 .
Table 3

Comparisons of Peak, Trough, End, and Beginning Happiness As Rated During the Holiday and at the Recall Tests

\begin{tabular}{llll}
\hline \multicolumn{1}{c}{ Comparisons } & $M$ & $S D$ & $r$ \\
\hline Peak happiness from text & 8.5 & 0.8 & \\
Happiest moment (from Test 1) & 8.3 & 1.6 & .27 \\
Happiest moment (from Test 2) & $8.0^{*}$ & 1.6 & $.83^{*}$ \\
Trough happiness from text & 2.4 & 1.3 & \\
Trough moment (from Test 1) & $3.2^{* *}$ & 1.8 & $.48^{*}$ \\
Trough moment (from Test 2) & $2.9^{* *}$ & 1.5 & $.80^{*}$ \\
Last 24 h from holiday data & 6.2 & 1.6 & \\
Last 24 h (from Graph 1) & 6.4 & 1.4 & $.62^{*}$ \\
Last 24 h (from Graph 2) & 5.6 & 1.9 & .09 \\
First 24 h from holiday data & 6.5 & 1.5 & \\
First 24 h (from Graph 1) & 6.5 & 1.5 & $.66^{*}$ \\
First 24 h (from Graph 2) & 6.3 & 1.7 & $.68^{*}$ \\
\hline
\end{tabular}

Note-The results of two-tailed $t$ tests are shown in the first column. The tests compare the value from the messages sent on the holiday with those obtained from the first and second recall tests. Note that the holiday mean actually compared with the second recall test may not be that shown in the table (because of missing data on the second test). Significant Pearson correlations with the overall text data are shown in the third column. $\quad{ }^{*} p<.05 . \quad{ }^{* *} p<.01$.

\section{The Peak-End Rule Within the Holiday}

Because we were sent daily records of the participants' best and worst moments over the previous $24 \mathrm{~h}$ as well as their level of happiness at the time of texting, it is possible to see whether the peak (or trough) end rule determines the average happiness for the preceding $24 \mathrm{~h}$ for each 24-h period of the participants' holidays. The issue is of some significance because, unlike much previously collected data (see, e.g., Fredrickson \& Kahneman, 1993; Redelmeier \& Kahneman, 1996), many of the text messages we were sent - peak and trough happiness and average happiness over the previous $24 \mathrm{~h}$-were retrospective reports already involving some degree of remembered affect. We constructed summary measures by first calculating correlations and means for each participant and then averaging over participants. The mean happiness rating over the previous $24 \mathrm{~h}$ was then $6.2(S D=1.1)$, in comparison with a mean happiness at the time of texting of 6.2 $(S D=1.1)$, mean peak-end happiness of $6.9(S D=1.0)$, and mean trough-end happiness of $5.1(S D=1.0)$. The

\section{Table 4}

Comparisons of the Overall Holiday Happiness Rating With Predictions From the "Remembered" Peak, End, and Beginning of the Holiday

\begin{tabular}{llll}
\hline & $M$ & $S D$ & $r$ \\
\hline Test 1 & & & \\
Overall holiday happiness & 6.8 & 1.4 & \\
"Remembered" peak end & 7.3 & $1.1^{*}$ & $.47^{*}$ \\
"Remembered" first 24 h & 6.5 & 1.5 & $.46^{*}$ \\
Test 2 & & & \\
Overall holiday happiness & 6.8 & 1.6 & \\
"Remembered" peak end & 6.8 & 1.6 & $.46^{*}$ \\
"Remembered" first 24 h & 6.5 & 1.8 & $.70^{*}$ \\
\hline
\end{tabular}

Notes - The results of two-tailed $t$ tests are shown in the first column. The tests compare the "remembered" ratings with the overall holiday rating at each test. Significant Pearson correlations with the overall holiday happiness rating for each test are shown in the third column. ${ }^{*} p<.05$. 
average correlations between happiness over the previous $24 \mathrm{~h}$ and happiness at text time, peak-end happiness, and trough-end happiness were, respectively, $0.48(S D=.35)$, $0.54(S D=.30)$, and $0.49(S D=.40)$.

\section{DISCUSSION}

At least two aspects of the results are in excellent agreement with previous findings on how people recall the affect of previous experiences, and they indicate that such findings can be generalized from briefer and more affectively homogeneous experiences to the longer and more varied experiences investigated in the present study. First, duration does not matter. Although the holidays were generally remembered as positive experiences, longer holidays did not receive higher overall ratings than did shorter ones. Second, the finding from previous research that people do not appear to remember and then average over an extensive sequence of past momentary experiences is replicated in the present data. Particularly crucial for this conclusion is the inability of the participants to recall the sequence of their happiness on the individual days of their holiday and frequent inconsistency in what they did recall. Indeed, often the participants were not particularly consistent even within a recall test. It is also noteworthy that the average happiness experienced over the holiday is significantly lower than the happiness that is recalled. Overall, our results are consistent with respondents basing their recall of overall happiness on only a limited sample of moments taken from the past event. Fredrickson and Kahneman's (1993) portrayal of memories for events as consisting of a few stills rather than of a continuous record seems rather a good description of the memories of our holiday takers.

The results do not support the primacy of the peak-end rule, regardless of whether one uses the trough or peak experience. The trough-end rule predicts that the holidays would be recalled as much less happy overall than they actually were. The peak-end rule predicts approximately the correct level of happiness, but the correlations of the peak-end average with the overall recalled happiness are generally lower than those obtained by considering the participants' happiness in the most memorable or most unusual 24-h period. There is even less support for the hypothesis that the peak and end affects are unusually well remembered, and that these well-remembered affects are preferentially used to produce the overall happiness rating. In brief, the data show both that peak, trough, and end happiness are not unusually well remembered, and that the estimates of peak, trough, and end happiness made in the recall tests are not especially well correlated with the overall recalled happiness.

Remembered overall happiness seems to be better predicted by end happiness than by peak or trough happiness, and the comparative failure of the peak-end rule appears to stem more from the peak than from the end. This is, perhaps, surprising in view of the expectation that one's last day might be atypical of the holiday as a whole, but the conclusion is clearly supported by the results shown in Tables 1 and 2. Note, however, that such atypicality may in- fluence one's feelings more at the time of the last text message than in the $24 \mathrm{~h}$ prior to that message. Recall that final text happiness correlates rather less well with subsequently recalled happiness than final 24-h happiness does.

The data also indicate reasons why the peak might not be a good predictor. In the first place, as Table 3 shows, the extreme affect appears to fade over time, just as previous researchers have found in other contexts (see, e.g., Walker et al., 1997). Second, there was little variation in the original peak affect rating: The majority of the respondents reported the highest possible rating of happiness at some moment on their holiday. One could argue that the peak-end rule might have fared better had we used a finer grain at the higher end of the happiness rating scale. On the other hand, at least one well-being theorist (Parducci, 1995) argued that higher overall happiness for an individual is obtained when life contains a large number of experiences that are peak experiences for that person and whose affect cannot be differentiated. If Parducci is correct, many reasonably happy people could be expected to have one such personal peak experience during an extended and relatively happy event, such as the holidays investigated here.

Our data also permitted some investigation of whether the peak-end rule held for individual days within people's holidays. Generally, the data suggest that the peak-end rule was a reasonable predictor of one's happiness estimate over the previous $24 \mathrm{~h}$, but it was no better a predictor than one's rated happiness at the time the messages were sent. These findings indicate that some results for the whole holiday appear also to hold reasonably well for individual days within the holiday.

Cojuharenco and Ryvkin (2007) found that the average happiness obtained by summing over the whole experience and the average of the peak and end experiences were highly correlated. We also found the different measures to be reasonably well correlated. Indeed, many of the different summary measures of holiday happiness (e.g., happiness during the first or last $24 \mathrm{~h}$; happiness during the most memorable moment) produced a moderately good prediction of the overall happiness evaluation obtained in later recall. One implication is that some people simply had (or consistently believed that they had) holidays that were overall happier than other people's holidays.

Consistent with other work on autobiographical memory, the present results show that memories of happiness are both changeable and liable to reconstruction. For example, peaks are recalled as less happy and troughs are recalled as less unhappy with time. The inability of participants to accurately recall the day-by-day changes in their holiday affect when they were asked to graph them in the tests indicates that many of the values that were estimated were either guesses or reconstructed. It is also possible that the participants' holidays were happier in retrospect because of the contrast with their normal lives, as seems to have happened with the homesick students of Burt et al. (1998).

If people do not estimate the happiness of an extended event by simply averaging the remembered peak and end experiences, then how do they do it? We think that it is 
likely that previous researchers, such as Fredrickson and Kahneman (1993), are right to have suggested that only a limited amount of information is available at any given recall time, and indeed, it is probable that, on occasion, this limited information includes the peak and end experiences. Other candidates include the beginning experience, the most unusual experience, or that thought most likely to be memorable at the time it happened. However, the available information might change systematically both with the fading of emotion and with the person's differing goals and circumstances at the time of recall. Consider, for example, if on a week's holiday you meet with old friends, see for the first time a beautiful scene, and have your laptop computer stolen. It seems probable that you will recall your holiday with greater affection in the context of talking about the old friends than when you try to replace the computer or its files. Finally, as the time since the holiday lengthens, less affect will generally be remembered, and more will be reconstructed. Fredrickson and Kahneman (1993) found some of their pleasant film clips became more pleasant and some less so, as the time since seeing them elapsed. They suggested that this phenomenon might have been caused by reconstruction: To take two of their examples, the idea of a puppy playing with a flower might seem more pleasant than waves breaking on a beach, but the latter might really have been more pleasant to watch. Over a relatively long and varied event such as a holiday, there are, of course, many opportunities for this kind of difference to emerge.

\section{AUTHOR NOTE}

We are grateful for a grant from the Psychology Department of the University of Canterbury. We also thank Richard Marsh, Jennifer Talarico, and two anonymous reviewers for their insightful and constructive feedback. We acknowledge and made use of Dr. Talarico's suggestion that our data enabled analysis of individual days within the holidays. Correspondence concerning this article should be addressed to S. Kemp, Psychology Department, University of Canterbury, Christchurch, New Zealand (e-mail: simon.kemp@canterbury.ac.nz).

\section{REFERENCES}

Ariely, D., \& CARMON, Z. (2003). Summary assessment of experiences: The whole is different from the sum of its parts. In G. Loewenstein, D. Read, \& R. F. Baumeister (Eds.), Time and decision: Economic and psychological perspectives on intertemporal choice (pp. 323-350). New York: Russell Sage Foundation.

Ariely, D., \& Loewenstein, G. (2000). When does duration matter in judgment and decision making? Journal of Experimental Psychology: General, 129, 508-523.

Ariely, D., \& Zauberman, G. (2000). On the making of an experience: The effects of breaking and combining experiences on their overall evaluation. Journal of Behavioral Decision Making, 13, 219-232.

BREWER, W. F. (1988). Memory for randomly sampled autobiographical events. In U. Neisser \& E. Winograd (Eds.), Remembering reconsidered: Ecological and traditional approaches to the study of memory (pp. 21-90). Cambridge: Cambridge University Press.

BurT, C. D. B. (1992). Reconstruction of the duration of autobiographical events. Memory \& Cognition, 20, 124-132.

Burt, C. D. B., Kemp, S., \& Conway, M. (2003). Themes, events, and episodes in autobiographical memory. Memory \& Cognition, 31, 317-325.

Burt, C. D. B., Kemp, S., \& Conway, M. (in press). Ordering the components of autobiographical events. Acta Psychologica.
Burt, C. D. B., Strongman, K. T., \& Costanzo, C. L. (1998). Memorial distortions and homesickness following relocation. Australian Journal of Psychology, 50, 106-113.

Christianson, S.-Å., \& Safer, M. A. (1996). Emotional events and emotions in autobiographical memories. In D. C. Rubin (Ed.), Remembering our past: Studies in autobiographical memory (pp. 218-243). Cambridge: Cambridge University Press.

CoJUHARENCO, I. (2007). Lay intuitions about overall evaluations of experiences. Judgment \& Decision Making, 2, 40-47.

Cojuharenco, I., \& RYVkin, D. (2007). Evaluations of experiences lived across time: Reconciling empirical findings with folk beliefs. Unpublished manuscript.

Conway, M. A. (2005). Memory and the self. Journal of Memory \& Language, 53, 594-628.

Conway, M. A., \& Pleydell-Pearce, C. W. (2000). The construction of autobiographical memories in the self-memory system. Psychological Review, 107, 261-288.

Fredrickson, B. L., \& Kahneman, D. (1993). Duration neglect in retrospective evaluations of affective episodes. Journal of Personality \& Social Psychology, 65, 45-55.

LEVINE, L. J. (1997). Reconstructing memory for emotions. Journal of Experimental Psychology: General, 126, 165-177.

Kahneman, D. (2000a). Evaluation by moments: Past and future. In D. Kahneman \& A. Tversky (Eds.), Choices, values, and frames (pp. 693-708). Cambridge: Cambridge University Press.

KAHNEMAN, D. (2000b). Experienced utility and objective happiness: A moment-based approach. In D. Kahneman \& A. Tversky (Eds.), Choices, values, and frames (pp. 673-692). Cambridge: Cambridge University Press.

Matt, G. E., VÁzQuez, C., \& CAMPBell, W. K. (1992). Mood-congruent recall of affectively toned stimuli: A meta-analytic review. Clinical Psychology Review, 12, 227-255.

PARDUCCI, A. (1995). Happiness, pleasure and judgment: The contextual theory and its applications. Mahwah, NJ: Erlbaum.

Redelmeier, D. A., \& Kahneman, D. (1996). Patients' memories of painful medical treatments: Real-time and retrospective evaluations of two minimally invasive procedures. Pain, 66, 3-8.

Redelmeier, D. A., Katz, J., \& Kahneman, D. (2003). Memories of colonoscopy: A randomized trial. Pain, 104, 187-194.

Rubin, D. C. (ED.) (1986). Autobiographical memory. Cambridge: Cambridge University Press.

Rubin, D. C. (ED.) (1996). Remembering our past: Studies in autobiographical memory. Cambridge: Cambridge University Press.

Rubin, D. C. (2005). A basic-systems approach to autobiographical memory. Current Directions in Psychological Science, 14, 79-83.

Schreiber, C. A., \& Kahneman, D. (2000). Determinants of the remembered utility of aversive sounds. Journal of Experimental Psychology: General, 129, 27-42.

Sheen, M., Kemp, S., \& Rubin, D. (2001). Twins dispute memory ownership: A new false memory phenomenon. Memory \& Cognition, 29, 779-788.

SHUM, M. S. (1998). The role of temporal landmarks in autobiographical memory processes. Psychological Bulletin, 124, 423-442.

Teasdale, J. D., Taylor, R., \& Fogarty, S. J. (1980). Effects of induced elation-depression on the accessibility of memories of happy and unhappy experiences. Behaviour Research \& Therapy, 18, 339-346.

Thomas, D. L., \& Diener, E. (1990). Memory accuracy in the recall of emotions. Journal of Personality \& Social Psychology, 59, 291-297.

Thompson, C. P., Skowronski, J. J., Larsen, S. F., \& Betz, A. L. (1996). Autobiographical memory: Remembering what and remembering when. Mahwah, NJ: Erlbaum.

Walker, W. R., Skowronski, J. J., \& Thompson, C. P. (2003). Life is pleasant - and memory helps keep it that way. Review of General Psychology, 9, 203-210.

Walker, W. R., Vogl, R. J., \& Thompson, C. P. (1997). Autobiographical memory: Unpleasantness fades faster than pleasantness over time. Applied Cognitive Psychology, 11, 399-413.

(Manuscript received March 6, 2007; revision accepted for publication May 15, 2007.) 